\title{
AN EFFECTIVE SOLUTION ON CENTRALIZED ACADEMICS BY USING AGILE METHODOLOGY WITH LARAVEL FRAMEWORK
}

\author{
Ravindra N. Jogekar, Pranay M. Meshram \\ Department of Computer Science and Engineering \\ Priyadarshini J. L. College of Engineering, Nagpur, Maharashtra, India
}

\begin{abstract}
The technology changes with changing in education system and methodology, students find many problems searching for right material and reference for learning. Due to lack of unavailability of centralized data and increasing irrelevancy in data, students struggle for study materials, and waste lots of time collecting question papers in the college computers and libraries. However, we always getting inappropriate study notes and rarely the accurate ones. Because of this, did our team take an initiative to revolutionize how we gather our syllabus related materials.

The agile methodology is the one we are taking to implement and execute our process. In agile methodology Extreme programming includes all the steps which are using for designing and development. The MVC model also uses to graph the flow chart and apply for real time implementation of our system. With the combination of Laravel framework, agile methodology and MVC model we are achieving the system to get dynamic functionalities.
\end{abstract}

Keywords - Agile Methodology, MVC model, Laravel Framework, Extreme Programming (XP)

\section{INTRODUCTION}

Research paper name gets the clear idea that this content is for students and it provide single portal for all the task which includes student module, admin module and institution module. Student Duniya serves as a platform that allows teachers to build online courses on topics which are suggesting and provide online videos for student. Student Duniya is an online portal that gives you free marketing and promotion by creating a course on the site, you have a potential audience of thousands of people.

To view training institute nearby and searching for internship or training of latest courses system provide tuition portal for the student as well as for the tutors. Website playing important role for providing better opportunities for students. The previous website also provides university-based question papers, but due to lengthy and step by step process take lots time for search, surf and download therefore this system overcome all the drawbacks to meet needs of the students.

Student Duniya helps to reduce time consuming process rather than go from three to four steps, it provides centralized hub of academic data for users to access whenever and wherever it is required and provide quick search option to get faster result as possible.

The agile methodology used for overall system process. In which unit testing takes role for testing the program and process. [1] The goal of Extreme programming(XP) is to improve software quality and responsiveness to changing customer requirements. Extreme programming improves a software project in essential ways. First is planning in which the project is divided in iterations. Second is managing in which team is given a dedicated open work space. Third is coding in which as per the standards, code is written, test driven development code is used. Fourth is designing. Last one is testing in which all code should be unit tested and should pass before it can be released.

MVC model known as model view controller are the major part for developing and connecting the system. [2] The MVC design provides ease in the process of web developing. The use of laravel framework helps the programmer in the development of large scale of applications that involve a lot of people in it. With the laravel framework, the code will be organized so that it can be easily understood by other programmers. In the web technology of three-tier structure, the database is not direct service to each client, but connecting to the web server, to achieve dynamic, real-time and interactive for customer information services. Web server acts as proxy for client, also a client for database. It will integrate information from different sources and different formats together into a unified interface to the client browser. 


\section{International Journal of Engineering Applied Sciences and Technology, 2019 \\ Vol. 3, Issue 11, ISSN No. 2455-2143, Pages 62-66 \\ Published Online March 2019 in IJEAST (http://www.ijeast.com)}

Laravel is a web application framework that tries to ease the development process but simplifying repetitive tasks used in most of today's web applications, including but not limited to routing, authentication, caching and sessions. This vertically integrated web development environment is meant to offer an improved and smooth workflow for the developer.

\section{PROPOSED METHODOLOGY}

Agile methodology is used for the development of laravel framework and it was followed by Extreme programming. The agile method is approach to proposed the management that is utilize in software development. This method assists teams in responding to the unpredictability of constructing software. Agile methods break the product into small incremental builds. The goal of Extreme Programming (XP) is to improve software quality and responsiveness to changing customer requirements. The unit testing used to check the quality of program.

Table 1.Comparision between Agile Methodology and Waterfall Model

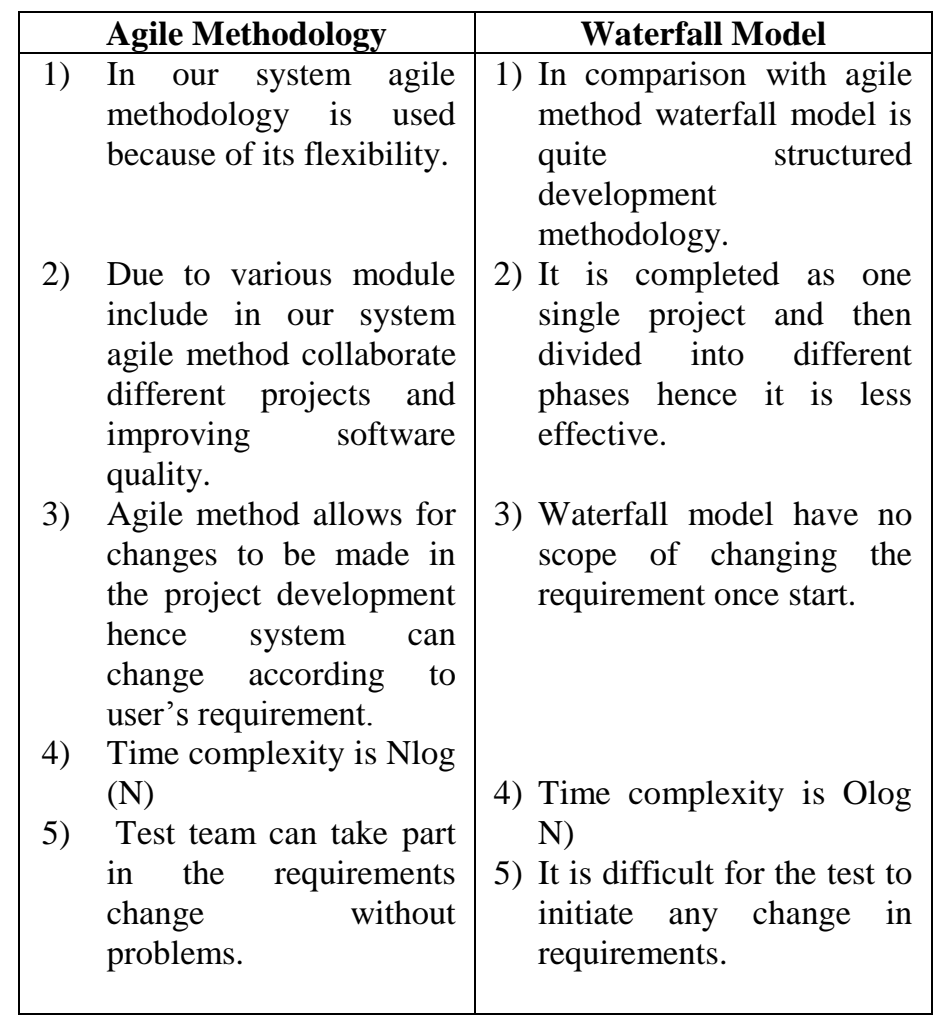

On the basis of such considerations and comparison of methodology adopted which is suitable for the larvae framework and provide the effective, correct, and fast result to the user. After selecting the methods we proceed with the Data flow for the environment that could be inculcate the data in the proper way of flow in the sequential manner. The first three steps are much more important for subsequent data process in depth of the data collection, analysis and further process for the defining objective and pre deployment phase and easy to develop content with blind testing and construct

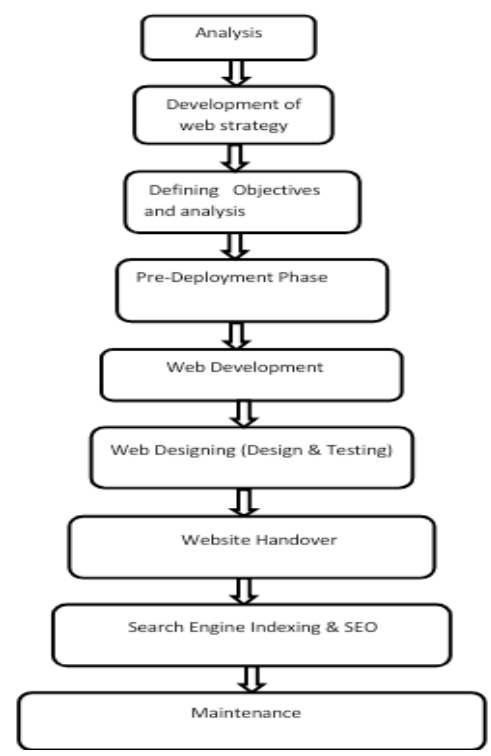

Fig. 1. Data Flow diagram for Agile methodology with laravel framework

III. System Architecture

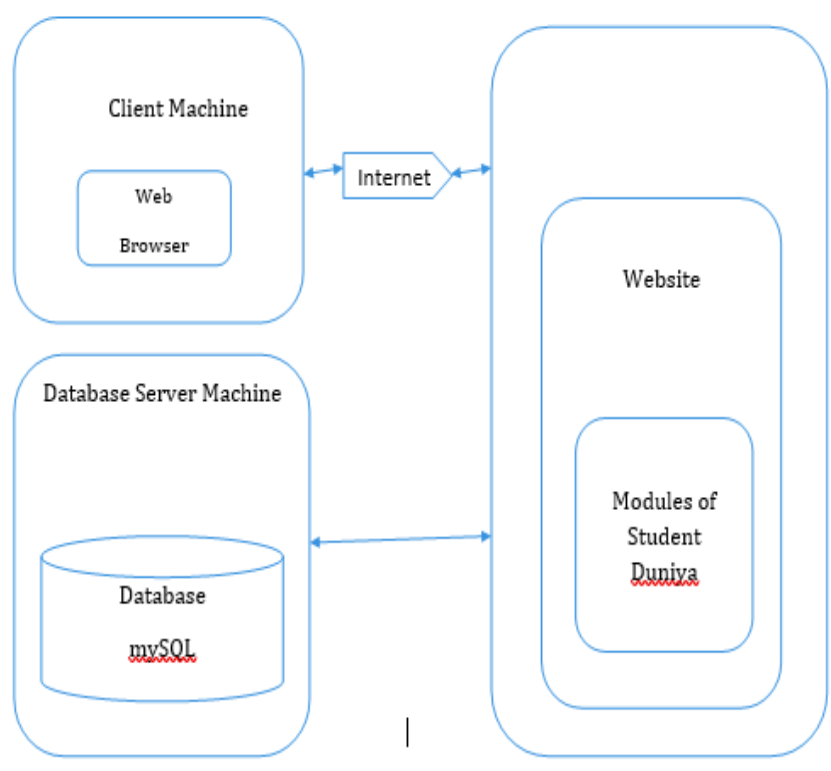

Fig. 2. System Architecture of laravel framework

\section{Detailed Structure}

The website has the functionality of login system which divided by two different categories namely student login and admin login. For accessing to the system, the profile will be created and then user maintains profile by themselves. The institutional head and admin panel having their own login 


\section{International Journal of Engineering Applied Sciences and Technology, 2019 \\ Vol. 3, Issue 11, ISSN No. 2455-2143, Pages 62-66 \\ Published Online March 2019 in IJEAST (http://www.ijeast.com)}

system which is differ from student or user. The information of user will safe with the website.

\section{System Design}

The following module shows the flow in a graphical way. It represents the flow from start to end to visualize the process of the project. We are having three main modules namely:

- Student module

- Institution module

- Admin module

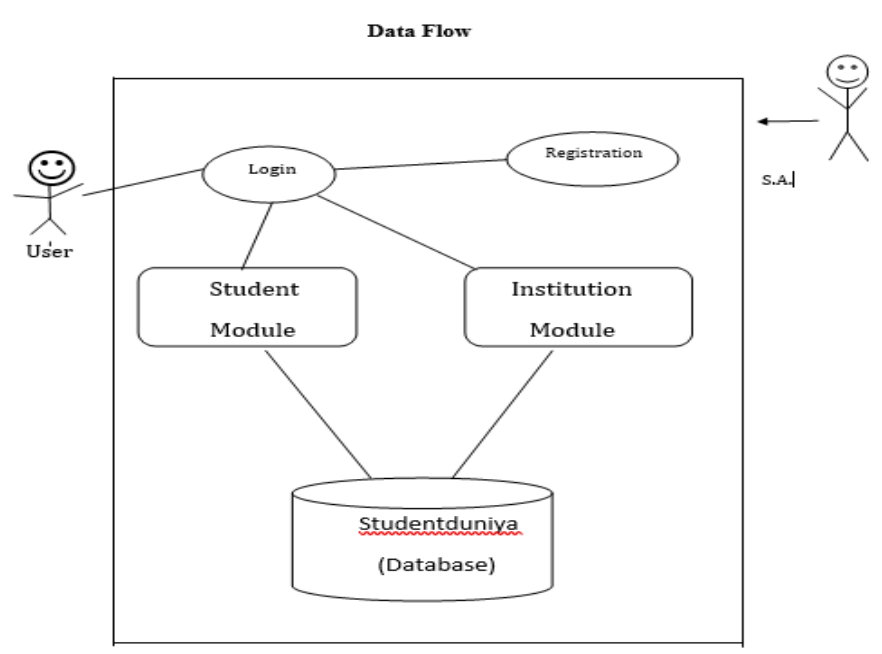

Fig. 3. Use Case Diagram for proposed framework

\section{Student module}

Student or user must create their own profile by registering themselves with fulfilling registration form

$\triangleright$ Student login with his/her email and password

$\gg$ Students fill his Personal Details, Educational Detail, Professional Detail

$\triangleright$ Student also view their details and make changes for their future opportunity.

\section{Institution module}

The institution module also has the registration process. After the registration they get their own portal or space to promote their institute and make their domain name followed by Student Duniya.

$\triangleright$ They can upload academics notes, make advertisement and upload videos

$\gg$ According to changes they can Add, Edit, Delete and update the information

$\triangleright$ It gets platform for themselves to promote their names and communicate with students

\section{Admin module}

Admin is the one who keeps track of all the operations within websites. Admin has a right to update and delete the data of user's if it seems inappropriate.

$$
\begin{aligned}
& \triangleright \text { Managed student details } \\
& >\text { View company details and approve company profiles } \\
& \triangleright \text { Managed and monitor company details }
\end{aligned}
$$

\section{III.EXPERIMENT AND RESULT}

The testing work by using agile methodology in laravel framework in unit tesing process. The results have been taken for every steps proposed in data flow diagram.

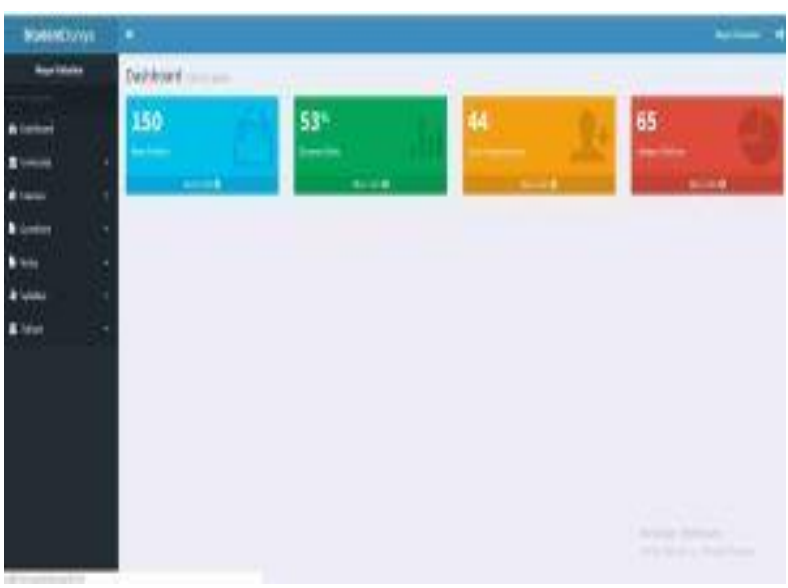

Fig. 4. Laravel Framework

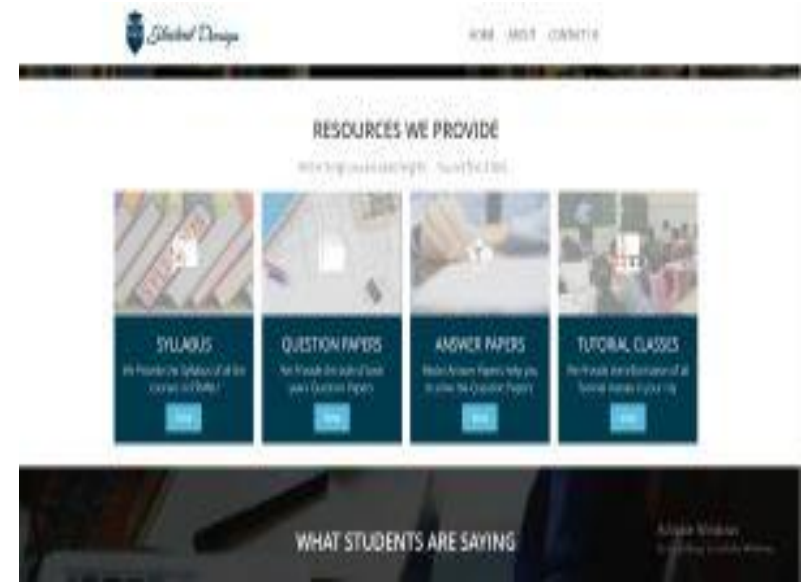

Fig. 5. Student and Tuition Model 


\section{International Journal of Engineering Applied Sciences and Technology, 2019 \\ Vol. 3, Issue 11, ISSN No. 2455-2143, Pages 62-66 \\ Published Online March 2019 in IJEAST (http://www.ijeast.com)}

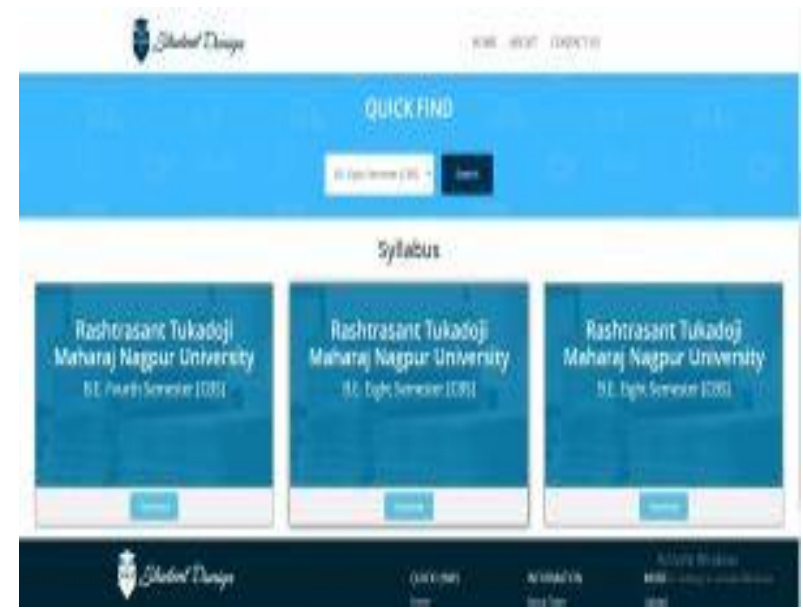

Fig. 6. Quick Find search button

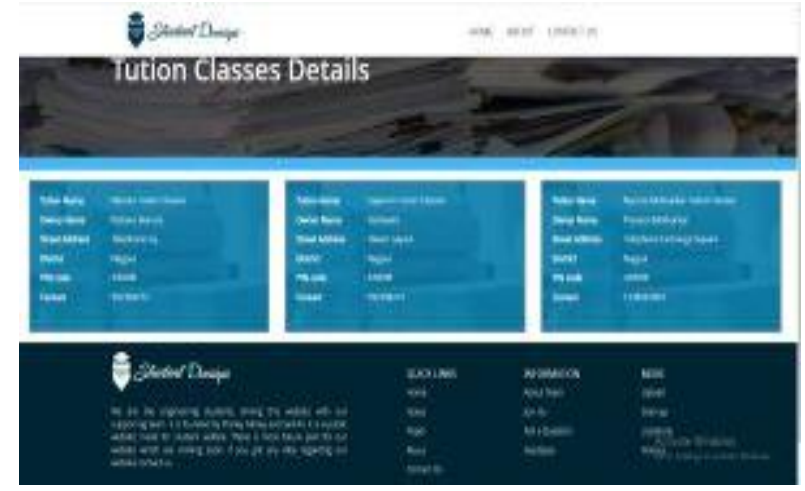

Fig. 7. Tuition Class Details

The previous system is also a website which is working on php domain but our project use MVC model to overcome the drawbacks of the existing website. In previous one the step by step and time-consuming process will be taken which results the slow processing. Our website provides the facility of study material with quick search box, fast download and search functionality. The institution module takes for private institutions to promoting their institutional name which gets them their domain name followed by Student Duniya and get contact of students through website.

Table .2 Comparative results Existing Academic Earth and Student Duniya

\begin{tabular}{|c|c|c|}
\hline & Academic Earth & $\begin{array}{c}\text { Student Duniya with } \\
\text { laravel framework }\end{array}$ \\
\hline Finiteness & $73 \%$ & $89 \%$ \\
\hline Development Hazards & $26 \%$ & $18 \%$ \\
\hline Methodology used & No & MVC \\
\hline
\end{tabular}

Table 2 shows the comparision between Academic Earth and Student duniya proposed by us. It could help out for proposing the actual adherence of the to the research people or the user of the system.

\section{OBJECTIVES}

$\checkmark \quad$ Provide online platform for a user to access, search, surf and download the academic notes.

$\checkmark \quad$ Reduce the access time

$\checkmark \quad$ Get detailed academics notes

$\checkmark \quad$ One platform for all task

\section{IV.CONCLUSION}

Student Duniya provides and help the student to get academic study notes or data and get quick access to information. This website reduces the time consuming and step by step process and provide efficient way to use, surf, search and download the academic data or materials. With the help of institutional module, the nearby institute and the study notes provided by different tutor's will be accessible for user if they are having their own profile at this website and all the process will be held in one platform.

\section{REFERENCE}

[1]Parkar Vishal et al, 2016, "Utilization of Laravel Framework for Development of Web Based Recruitment Tool", Department of Computer Engineering,Rajendra Mane College of Engineering and Technology, India , eISSN: 2278-0661,p-ISSN: 2278-8727, pg.36-41.

[2]Gaurav Kumar, Pradeep Kumar Bhatia, August 2014 "Impact of Agile methodology on Software Development Process" International Journal of Computer Technology and Electronics Engineering (IJCTEE) Volume 2, Issue 4,pg.4650.

[3]Jamal Armel, April 2014 "Web application development with Laravel PHP Framework" Helsinki Metropolia University of Applied Sciences.

[4]HE REN YU,2014 "Design and Implementation of web based on Laravel framework" Nankai University Binhai College,International Conference on Computer Science and Electronic Technology (ICCSET),pg.301-304.

[5]Neil B. Harrison, 2014,"A Study of Extreme Programming in a Large Company"pg. https://www.researchgate.net/publication/250790483

[6] Thakur Sonia et al, "Role of Agile Methodology in Software Development" International Journal of Computer Science and Mobile Computing Vol.2 Issue. 10, October2013, pg. 86-90.

[7]Radmila Juric, 2000, Proceedings of the 22nd International Conference on Information Technology Interfaces, ITI 2000, 
13-16 June 2000, Pula, Croatia. IEEE, pp.97-104. ISBN 9539676916

[8]Jogekar Ravindra, et. al. 2019 "Student Duniya for providing Centralized Academics Solutions" ICIREST-19, TGPCET, Nagpur

[9]https://www.theseus.fi/bitstream/handle/10024/113987/thesi s_laravel5-

final_31_05_2016.pdf? sequence=1\&isAllowed=y

[10] https://www.guru99.com/waterfall-vs-agile.html

[11] https://www.altexsoft.com/media/2016/04/Agile-

Project-Management-Best-Practices-and-Methodologies-

Whitepaper.pdf

[12] https://pdfs.semanticscholar.org/887a/2727beff01d9c 1eec52001c79ec9590d4591.pdf

[13] https://ntrs.nasa.gov/archive/nasa/casi.ntrs.nasa.gov/2 0030012934.pdf 